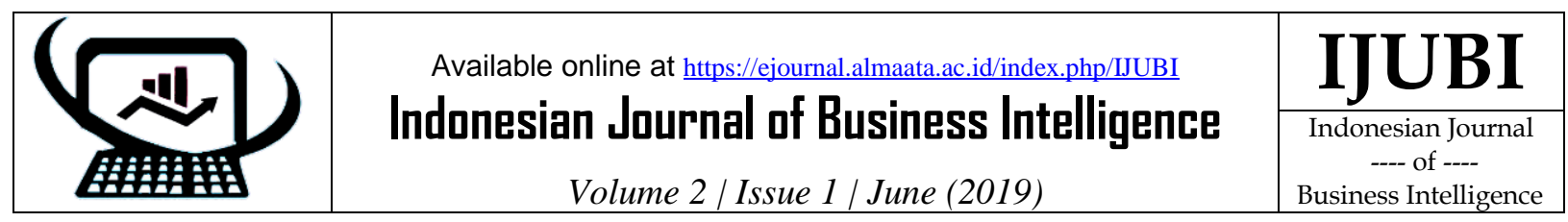

\title{
PENDETEKSIAN MINAT DAN BAKAT MENGGUNAKAN METODE RIASEC
}

Fiyan Kurnia Hidayat ${ }^{1}$, Sri Ngudi Wahyuni ${ }^{2}$

${ }^{1}$ Informatika, Fakultas Ilmu Komputer, Universitas AMIKOM Yogyakarta

2 Manajemen Informatika, Fakultas Ilmu Komputer, Universitas AMIKOM Yogyakarta

${ }^{1}$ fiyan.hi@gmail.com, ${ }^{2}$ yuni@amikom.ac.id

${ }^{12}$ J1. Ringroad Utara, Condongcatur, Depok, Sleman, Yogyakarta

Keywords:
Interests, RIASEC,
Probability

Kata Kunci

Peminatan, RIASEC, Probabilitas

\begin{abstract}
The interests are very important to choosing a course and field of work. Good salary, good company is one of goal in our life. One of many way which we can do for choice and mapping it more early is interest detection for detect our school and faculty which suitable with our interest. One of interest detection method use is RIASEC. RIASEC is one method with use probability principles for compute and compare six elements in it. The expensive price for buying a psychology expert is reason for developing this systems. The system can access bay website and which easy way. It will be helping all people for detection their children interest and will can giving best education for them.
\end{abstract}

\section{Abstrak}

Minat sangat penting untuk memilih kursus dan bidang pekerjaan. Gaji yang baik, perusahaan yang baik adalah salah satu tujuan dalam hidup kita. Salah satu cara yang dapat kita lakukan untuk memilih dan memetakannya lebih awal adalah deteksi minat untuk mendeteksi sekolah dan fakultas kita yang sesuai dengan minat kita. Salah satu metode pendeteksian minat yang digunakan adalah RIASEC. RIASEC adalah salah satu metode dengan menggunakan prinsip probabilitas untuk menghitung dan membandingkan enam elemen di dalamnya. Harga mahal untuk membeli seorang ahli psikologi adalah alasan untuk mengembangkan sistem ini. Sistem ini dapat mengakses situs web rongga dan cara yang mudah. Ini akan membantu semua orang untuk mendeteksi minat anak-anak mereka dan akan dapat memberikan pendidikan terbaik untuk mereka.

\section{Pendahuluan}

Minat adalah suatu hal yang disukai contoh minat jurusan kuliah, bidang pekerjaan, dan profesi dan lain sebagainya. Tidak semua orang tahu apa yang menjadi minat dirinya. Sehingga perlu konsultasi ke psikolog, tetapi mahalnya biaya konsultasi dan lamanya hasil deteksi minat menyebabkan orang enggan untuk mendeteksi minat dan bakart mereka. Minat dan bakat sangat penting dalam menentukan jurusan kuliah, profesi ataupun pekerjaan pekerjaan. System pakar untuk pendeteksian minat dan bakat adalah salah satu alternative yang ditempuh untuk memecahkan permasalahan tersebut. Salah satu model yang

32 "Fiyan Kurnia Hidayat" digunakan untuk pendeteksian minat dan bakat adalah model RIASEC.

Hedrih, et all (2016) pada penelitiannya menggunakan RIASEC untuk deteksi karir pada remaja di Bulgaria dan Serbia. Penelitian tesebut menyatakan bahwa hasilnya valid, hamper 90\% hasilnya dianggap baik [1]. Saadullah, et, all (2017) membahas tentang pemanfaatan model RIASEC untuk mendeteksi minat mahasiswa jurusan akuntansi untuk memaksimalkan kinerja mahasiwa [2].

Holland (2016) melakukan penelitian untuk memetakan minat seseorang menjadi 6 kriteria yang ada di model RIASEC, yaitu realistis, investigatif, artistik, sosial, enterprising, dan konvensional. Proses analisis dilaksanakan 
dengan mengisi kuisioner berisikan ciri-ciri atau karakter yang ada di model RIASEC. Setiap ciri-ciri sudah dikelompokkan sesuai dengan minat dan bakat. Hasil akan menampilkan nilai tertinggi dari kriteria yang dipilih. Dari hasil tersebut akan direkomendasikan profesi, pekerjaan ataupun jurusan pendidikan yang bisa dipilih oleh user.

Moyo-Acerado (2014) menyatakan bahwa RIASEC dapat digunakan untuk membantu mahasiswa untuk memilih kensentrasi dan jurusan kuliah. Penelitian ini membangun sistem untuk mengarahkan mahasiswa kepada matakuliah konsentrasi yang sesuai dengan minat dan bidangnya, yaitu konsentrasi Manajer Operasi, Perancang Antarmuka Pengguna, dan Pengembang Aplikasi. Proses identifikasi bertujuan untuk pemilihan konsentrasi paling cocok untuk mereka pilih sesuai dengan pengetahuan, keterampilan, nilai-nilai dan minat mereka. RIASEC digunakan di Belanda untuk menentukan minat yang paling dominan dan nilai-nilai yang paling dominan dari para ahli komputasi industry. Artinya RIASEC mampu digunakan untuk semua bidang, baik pendidikan maupun industry [3].

Penelitian serupa juga dilakukan oleh Aljojol dan Saifuddin (2017) menganalisa validitas model RIASEC di Belanda untuk diimplementasikan di arab dengan menggunakan bahasa arab. Penelitian ini membahas tentang isi RIASEC ketika diimplementasi di lingkungan Arab terdapat masalah terutama masalah budaya. Penelitian ini mengambil sampel pada 178 siswa di Universitas King Abdulaziz. Ada 3 hal yang harus diteliiti untuk validitas Model RIASEC di Belanda yaitu reliabilitas internal, struktur factor, dan analisis korelasi. Dari hasil penelitian ini disimpulkan bahwa korelasi antar kepribadian di kejuruan di Belanda dan Arab terbukti memiliki korelasi positif sehingga bisa dikatakan valid [4].

\section{Landasan Teori}

\section{Teori Holand}

Personality Type Theory atau Teori Tipe Kepribadian adalah teori yang dikemukakan oleh John Holland yang menyatakan bahwa sebuah usaha harus dilakukan untuk mencocokkan pilihan karir individu dengan kepribadiannya [5].sebagai contoh 5 kombinasi SDS Code diantaranya adalah sebagai berikut:

1. Kombinasi kode ringkas SEI dengan saran pekerjaan Psychologist dan Counseling.

2. Kombinasi kode ISC dengan saran pekerjaan sebagai berikut:
a. Computer Network Support Specialist
b. Dialiysis Technician
c. Linguist
d. Market Research Analyst
e. Microbiologist
f. Physician
g. Research Asssistant
h. Translator

3. Kombinasi kode CSI dengan saran pekerjaan
a. Accounting and Computer Sciences
b. Computer Support Specialist
c. Health Information/Medical Records Technology/Technician

4. Kombinasi kode SCI dengan saran pekerjaan sebagai Community Health Worker dan Optometri Assistant

5. Kombinasi kode SEC dengan saran pekerjaan sebagi Social Worker [6].

Menurut Holland, jika individu menemukan karir yang sesuai dengan kepribadiannya, maka individu tersebut akan menikmati karirnya tersebut dan dapat bertahan cukup lama. Holland mengemukakan tentang 6 kepribadian dasar yang harus dipertimbangkan ketika menyesuaikan keadaan psikologis individu dan karir. Keenam kepribadian dasar tersebut adalah sebagai berikut:

\section{Realistic}

Individu dengan kepribadian tersebut lebih suka berinteraksi dengan dunianya melalui ekspresi artistik, cenderung menghindari situasi yang konvensional dan interpersonal. 
Individu tersebut lebih baik berorientasi pada karis seperti seni dan menulis.

Adapun ciri-ciri kepribadian ini adalah:

a. Kemampuan mekanikal, psikomotor, dan atletik yang baik.

b. Jujur.

c. Setia

d. Suka kegiatan-kegiatan diluar

e. Lebih suka bekerja dengan mesin, alat-alat, tumbuhan, dan hewan.

f. Lebih menyukai kegiatan-kegiatan yang bersifat fisik.

g. Lebih menyukai kegiatan kongkrit.

h. Tidak terlalu suka bersosialisai.

i. Tidak suka hal-hal yang kompleks (lebih mneyukai kesederhanaan)

j. Individu dengan kepribadian tersebut lebih baik memilih karir-karir yang bersifat praktis, seperti buruh, bertani, supir truk, dan konstruksi.

\section{Investigative}

Individu dengan kepribadian ini lebih berorientasi pada konsep dan teori. Mereka lebih berperan sebagai pemikir daripada sebagai pelaksana. Mereka sering menghindari adanya hubungan interpersonal dan lebih sesuai dengan karir-karir yang berkaitan dengan matematika dan pengetahuan. Adapun ciri-cirinya adalah:

a. Kemampuan memecahkan masalah dan analitis yang baik.

b. Cenderung berfikir matematis.

c. Suka mengobservasi, mempelajari, dan mengevaluasi.

d. Lebih suka bekerja sendiri.

e. Pemberi ide.

f. Hati-hati, kritis, dan selalu ingin tahu

g. Suka kedisiplinan.

h. Berorientasi tugas.

i. Sistematis

\section{Artistic}

a. Berpikir abstrak.

b. Menyukai estetika (keindahan).

c. Kreatif, suka hal-hal kompleks, emosional, intuitif, ideal.

d. Lebih suka bekerja secara mandiri.

e. Suka menyanyi, berakting, menulis, dan melukis.

f. Imaginatif.

g. Tidak suka hal-hal yang konvensional.

h. Tidak dapat diduga.

i. Tidak suka keteraturan.

\section{Social}

Individu ini memiliki kemampuan verbal dan hubungan interpersonal yang baik. Mereka lebih cocok memasuki dunia karir yang berhubungan dengan manusia seperti mengajar, pekerja sosial, konseling, dan semacamnya. Adapun ciri-cirinya adalah:

a. Komunikatif.

b. Bersahabat, mudah bergaul.

c. Suka memberi dan membantu.

d. Baik, impulsive.

e. Bertanggung jawab.

f. Berjiwa kelompok.

g. Mempunyai toleransi yang cukup baik.

h. Dapat memahami.

i. Kemampuan verbal dan personal yang baik.

\section{Enterprising}

Individu ini menggunakan kemampuan verbalnya untuk memimpin orang lain, mendominasi individu, dan menjual produk atau hal yang lain. Individu ini lebih sesuai dalam karir seperti sales, bidang politik, dan manajemen.

Adapun ciri-ciri kepribadian ini adalah:

a. Percaya diri, bersikap asertif.

b. Mudah beradaptasi.

c. Ambisisus. 
d. Kemampuan berbicara dan memimpin yang baik.

e. Suka menggunakan pengaruh seseorang.

f. Kemampuan interpersonal yang cukup baik.

g. Penuh energi, ekstrovert, optimis, persuasif.

h. Suka mengambil resiko, spontan.

i. Suka mengontrol.

\section{Conventional}

Individu ini lebih menyukai kegiatan yang bersifat terstruktur. Mereka lebih suka pekerjaan yang berupa bawahan seperti pegawai bank, sekretaris, dan petugas arsip. Adapun ciri-ciri kepribadian ini adalah:

a. Tergantung pada orang lain.

b. Tidak kreatif.

c. Suka kedisiplinan dan ketepatan.

d. Suka memperhatikan detail.

e. Efisien.

f. Melaksanakan tugas secara teratur.

g. Kemampuan klerikel dan numerical yang baik.

h. Terorganisir.

i. Bersifat tradisional.

Adapun tabel minat dijelaskan pada Tabel 1. Yaitu Tabel Data tipe minat.

Tabel 1. Data Tipe Minat

\begin{tabular}{c|l}
\hline No & \multicolumn{1}{|c}{ Tipe Minat } \\
\hline 1 & Realistis \\
2 & Investigatif \\
3 & Artistik \\
4 & Sosial \\
5 & Enterprising \\
6 & Konvensional \\
\hline
\end{tabular}

Selain data minat, berikut adalah Data Ciri-ciri Kepribadian, data ciri-ciri kepribadian yang akan menentukan jenis kepribadian seseorang [7], dijelaskan pada Table 2.

Tabel 2. Data Ciri-ciri Kepribadian

\begin{tabular}{c|l}
\hline No & \multicolumn{1}{|c}{ Ciri-ciri Kepribadian } \\
\hline 1 & Saya tidak suka hal yang kompleks \\
2 & Saya suka membangun sesuatu \\
\hline
\end{tabular}

\begin{tabular}{|c|c|}
\hline No & Ciri-ciri Kepribadian \\
\hline 3 & Saya suka merawat hewan \\
\hline 4 & $\begin{array}{l}\text { Saya suka menyatukan sesuatu atau } \\
\text { merakit sesuatu }\end{array}$ \\
\hline 5 & Saya suka memasak \\
\hline 6 & Saya orang yang praktis (suka yang simple) \\
\hline 7 & $\begin{array}{l}\text { Saya suka bekerja di luar ruangan } \\
\text { (Outdoor) }\end{array}$ \\
\hline 8 & Saya orang yang jujur \\
\hline 9 & Saya tidak suka bersosialisasi \\
\hline 10 & $\begin{array}{l}\text { Saya suka dengan tugas-tugas yang } \\
\text { kongkrit }\end{array}$ \\
\hline 11 & Saya suka mengerjakan puzzle \\
\hline 12 & Saya suka melakukan eksperimen \\
\hline 13 & $\begin{array}{l}\text { Saya suka dengan sesuatu yang } \\
\text { berhubungan dengan sains }\end{array}$ \\
\hline 14 & $\begin{array}{l}\text { Saya senang mencoba mencari tahu } \\
\text { bagaimana segala sesuatu itu berjalan }\end{array}$ \\
\hline 15 & $\begin{array}{l}\text { Saya suka menganalisis berbagai hal } \\
\text { (masalah / situasi) dan mengevaluasi }\end{array}$ \\
\hline 16 & $\begin{array}{l}\text { Saya suka bekerja dengan angka atau } \\
\text { bagan (Matematis) }\end{array}$ \\
\hline 17 & \\
\hline 18 & \\
\hline 19 & Saya o \\
\hline 20 & $\begin{array}{l}\text { Saya suka menjabarkan sesuatu secara } \\
\text { teratur dan logis }\end{array}$ \\
\hline 21 & bekerja secara mandiri \\
\hline 22 & nusic \\
\hline 23 & krea \\
\hline 24 & kreatif \\
\hline 25 & $\begin{array}{l}\text { Saya suka memainkan alat musik atau } \\
\text { bernyanyi }\end{array}$ \\
\hline 26 & \\
\hline 27 & \\
\hline 28 & \\
\hline 29 & \\
\hline 30 & \\
\hline 31 & \\
\hline 32 & u melatih orang lain \\
\hline 33 & $\begin{array}{l}\text { mbantu orang } \\
\text { eka }\end{array}$ \\
\hline 34 & \\
\hline 35 & \\
\hline 36 & $\begin{array}{l}\text { Saya suka berdiskusi tentang suatu } \\
\text { masalah }\end{array}$ \\
\hline 37 & Saya suka membantu orang \\
\hline 38 & $\begin{array}{l}\text { Saya orangnya bersahabat dan mudah } \\
\text { bergaul }\end{array}$ \\
\hline 39 & anggungjawab \\
\hline 40 & $\begin{array}{l}\text { Saya orang dengan rasa toleransi yang } \\
\text { tinggi }\end{array}$ \\
\hline 41 & $\begin{array}{l}\text { Saya adalah orang yang ambisius, saya } \\
\text { menetapkan tujuan untuk diri saya sendiri }\end{array}$ \\
\hline 42 & $\begin{array}{l}\text { Saya suka mencoba mempengaruhi atau } \\
\text { membujuk orang }\end{array}$ \\
\hline
\end{tabular}

IJUBI - Vol. 2 No. 1 (2019): 32 - 39 


\begin{tabular}{c|l}
\hline No & \multicolumn{1}{|c}{ Ciri-ciri Kepribadian } \\
\hline 43 & Saya suka berjualan \\
44 & Saya cepat mengambil tanggung jawab \\
& baru \\
45 & Saya ingin memulai bisnis saya sendiri \\
46 & Saya suka memimpin \\
47 & Saya suka berpidato \\
48 & Saya orangnya mudah beradaptasi \\
49 & Saya orangnya suka mengambil resiko dan \\
50 & spontan \\
& $\begin{array}{l}\text { Saya orangnya percaya diri, tegas, dan juga } \\
\text { mampu mengutarakan sesuatu yang ada di } \\
\text { hati dan fikiran saya tetapi tetap terkontrol }\end{array}$ \\
51 & $\begin{array}{l}\text { Saya suka mengatur sesuatu, (file, meja / } \\
\text { kantor) }\end{array}$ \\
52 & $\begin{array}{l}\text { Saya ingin memiliki instruksi yang jelas } \\
\text { untuk diikuti }\end{array}$ \\
53 & Saya tidak keberatan bekerja 8 jam sehari di \\
kantor \\
54 & Saya memperhatikan sesuatu secara detail \\
55 & Saya suka melakukan pengarsipan atau \\
pengetikan
\end{tabular}

Holland mengembangkan kuesioner Vocational Preference Inventory yang berisi 160 pekerjaan. Responden memilih pekerjaan yang disukai atau tidak disukainya dan jawaban digunakan untuk membentuk profil kepribadiannya. Cara untuk mengidentifikasi karir digambarkan dengan sebuah heksagon. Sebuah heksagon menggambarkan kesamaan dan perbedaan karakteristik diantara orang, diantara pekerjaan, dan diantara orang dan pekerjaan. Hanya sedikit orang yang memiliki satu tipe. Biasanya setiap orang memiliki dua tipe atau lebih. Tipe data heksagon yang bersebelahan lagsung merupakan kombinasi tipe yang erat hubungannya. Tipe yang berseberangan merupakan tipe yang yang paling tidak berhubungan. Contohnya tipe Realistic dan Investigative serupa, namun Realistic dan Social bertolak belakang. Adapun metode HOLLAND digambarkan pada Gambar 1.

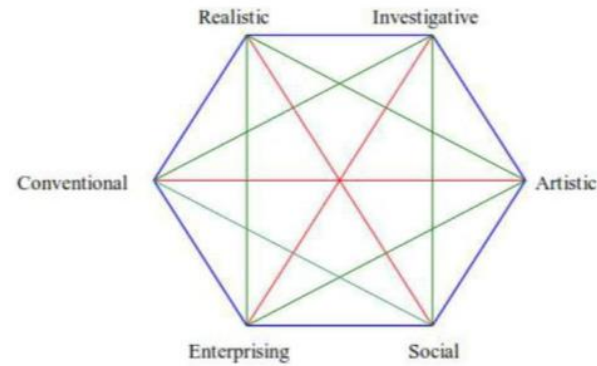

Gambar 1. Heksagon dari Holland

\section{Metode Penelitian}

Metode penelitian yang digunakan pada penelitian ini tertera pada gambar 2 .

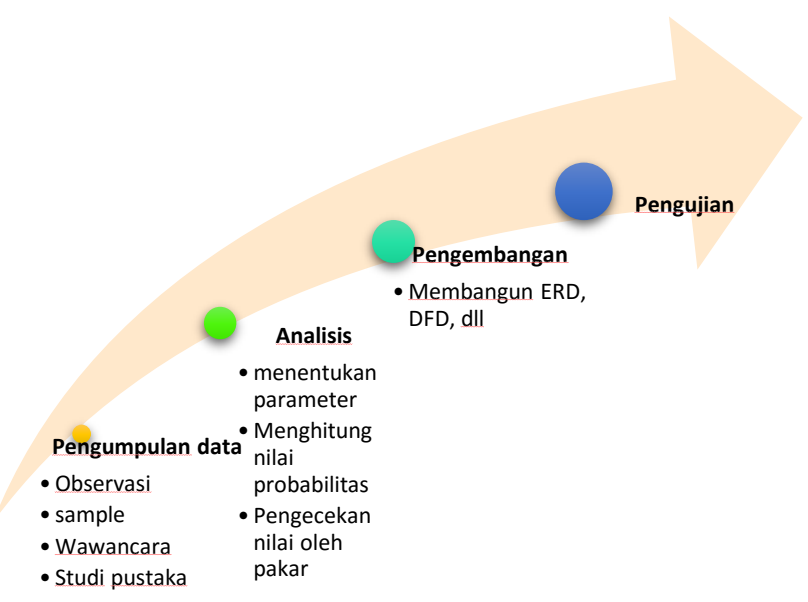

Gambar 2. Metode penelitian

Tahap pertama adalah tahap pengumpulan data. Adapun Langkah-langkah pada tahapan ini adalah:

- Data-data dikumpulkan dengan mempelajari, meneliti dan memahami berbagai literature baik dalam buku, jurnal ilmiah.

- Metode Observasi, melakukan observasi dengan obyek permasalahan anak SMA.

- Metode Wawancara, dilakukan dengan melakukan wawancara kepada seorang pakar psikolog.

Tahapan kedua adalah tahapan analisis dengan melakukan beberapa hal dibawah ini, antara lain:

- Analisis Kebutuhan Sistem, Didalam penelitian ini dipilih solusi yang paling mungkin diterapkan dengan segera yaitu. 
Sistem Pendeteksi Minat menggunakan model RIASEC berbasis Website.

- Kebutuhan Fungsional Fungsional Admin, antara lain:

a. Sistem harus dapat menampilkan menu login

b. Admin dapat melakukan login untuk dapat mengakses menu admin

c. Sistem harus dapat melakukan pengolahan data tipe minat

d. Admin dapat melihat data tipe minat

e. Admin dapat melakukan penambahan data tipe minat

f. Admin dapat melakukan update data tipe minat

g. Admin dapat menghapus data tipe minat

h. Sistem harus dapat melakukan pengolahan data ciri-ciri untuk menentukan tipe minat

i. Admin dapat melihat data ciri-ciri untuk menentukan minat

j. Admin dapat melakukan penambahan ciri-ciri untuk menentukan minat

k. Admin dapat melakukan update data ciri-ciri untuk menentukan minat

1. Admin dapat menghapus data ciri-ciri untuk menentukan minat

m. Sistem harus dapat melakukan pengolahan data password

n. Admin dapat mengganti password lama

o. Admin dapat melakukan konfirmasi password baru

p. Sistem harus dapat melakukan data pengolahan hasil output

q. Admin dapat melihat data hasil output

1. Kebutuhan Fungsional Pengguna

r. Sistem harus dapat menampilkan informasi tipe minat

- Kebutuhan Non Fungsional, yaitu menentukan spesifikasi untuk computer yang digunakan untuk menjalankan system dan kebutuhan perangkat lunak.
- Kebutuhan Informasi, hasil yang diharapkan daro aplikasi ini adalah menjadi pengganti pakar untuk para remaja terutama siswa SMA dalam mengetahui sejak dini minat yang ada pada dirinya dan juga pengetahuan serta saran pekerjaan yang sesuai dengan minatnya. Dalam hal ini apabila user ingin lebih detail lagi dalam mengetahui minat serta saran yang lebih lengkapnya, diharapkan untuk konsultasi langsung kepada psikolog.

Tahap ketiga adalah tahapan analisis, antara lain:

1. Pengolahan data parameter (ciri-ciri kepribadian untuk menentukan minat) yang digunakan untuk menentukan minat meliputi insert, update, delete pada seluruh data. Dengan fitur ini, hasil yang didapatkan akan lebih dinamis.

2. Menghitung nilai probabilitas kepribadian untuk menentukan minat yang diambil sesuai dengan model RIASEC berdasarkan teori Holland. dibuat oleh Holland.

3. Pengecekan nilai oleh Pakar.

\section{Pembahasan}

Pada prinsipnya untuk menentukan minat dan bakat dengan metode RIASEC adalah penggunaan probabilitas. Probabilitas digunakan untuk mendapatkan hasil yang dengan membandingkan satu peluang dengan peluang lainnya. Adapun teorema Probabilitas yang digunakan adalah seperti pada rumus dibawah ini.

$$
P(\alpha)=\frac{n}{N}
$$

Keterangan $=$

- $P(a)=$ Peluang variable $a($ tipe minat $)$

- $\mathrm{a}=$ Tipe minat (Realistis, Investigatif, Artistik, Sosial, Enterprising, Convensional)

- $\mathrm{n}$ = hasil/sampel (ciri-ciri kepribadian yang dipilih user per variable)

- $\mathrm{N}=$ populasi (total ciri-ciri kepribadian per variable)

- Teorema Probabilitas dan Perbandingan 


$$
P(\alpha 1) \text { Terhadap } P(\alpha 2)=\frac{p(\alpha 1)}{p(\alpha 2)}
$$

Contoh Kasus:

Berikut adalah hasil dari tes minat diperoleh yaitu:
a. $\mathrm{R}($ Realistik $)=8$
b. I (Investiogatif $=7$
c. $\mathrm{A}($ Artistik $)=8$
d. $S($ Sosial $)=4$
e. $\mathrm{E}($ Enterpreneur $)=8$
f. $C($ Convensional $)=4$

Penyelesaian:

1. Perhitungan menggunakan teorema probabilitas tiap variabelnya

a. Realistik (R)

Diketahui nilai $\mathrm{n}=8$ dan $\mathrm{N}=10$

$P(R)=\frac{n}{N}=\frac{8}{10}=0.8$

b. Investigatif (I)

Diketahui nilai $\mathrm{n}=7$ dan $\mathrm{N}=10$

$$
P(I)=\frac{n}{N}=\frac{7}{10}=0.7
$$

c. $\operatorname{Artistik}(\mathrm{A})$

Diketahui nilai $\mathrm{n}=8$ dan $\mathrm{N}=10$

$$
P(A)=\frac{n}{N}=\frac{8}{10}=0.8
$$

d. Sosial (S)

Diketahui nilai $\mathrm{n}=4$ dan $\mathrm{N}=10$

$$
P(A)=\frac{n}{N}=\frac{4}{10}=0.4
$$

e. Enterprising/Enterpreneur

Diketahui nilai $\mathrm{n}=8$ dan $\mathrm{N}=10$

$$
P(E)=\frac{n}{N}=\frac{8}{10}=0.8
$$

f. Convensional (C)

Diketahui nilai $\mathrm{n}=4$ dan $\mathrm{N}=10$

$$
P(C)=\frac{n}{N}=\frac{4}{10}=0.4
$$

Dari data diatas disimpulkan nilai tertinggi ialah $\mathrm{P}(\mathrm{R}), \mathrm{P}(\mathrm{A})$, dan $\mathrm{P}(\mathrm{E})$ dimana probabilitas tersebut adalah Realistik, Artistik, dan
Enterprising. Jadi usr Latif memiliki kecenderungan minat di Realistik, Artistik, dan Enterprising.

Teorema Probabilitas dan Perbandingan

a. Perbandingan antara Probabilotas variable $\mathrm{R}$ terhadap I

$$
P(\alpha 1) \text { Terhadap } P(\alpha 2)=\frac{p(R)}{p(I)}=\frac{0,8}{0,7}=\frac{8}{7}
$$

b. Perbandingan antara Probabilotas variable $\mathrm{R}$ terhadap $\mathrm{A}$

$$
\begin{gathered}
P(\alpha 1) \text { Terhadap } P(\alpha 2)=\frac{p(R)}{p(A)}=\frac{0,8}{0,8}=\frac{8}{8} \\
=1
\end{gathered}
$$

c. Perbandingan antara Probabilotas variable R terhadap S

$P(\alpha 1)$ Terhadap $P(\alpha 2)=\frac{p(R)}{p(S)}=\frac{0,8}{0,4}=\frac{8}{4}$

d. Perbandingan antara Probabilotas variable $\mathrm{R}$ terhadap $\mathrm{E}$

$P(\alpha 1)$ Terhadap $P(\alpha 2)=\frac{p(R)}{p(E)}=\frac{0,8}{0,8}=\frac{8}{8}$

$$
=1
$$

e. Perbandingan antara Probabilotas variable $\mathrm{R}$ terhadap $\mathrm{C}$

$$
P(\alpha 1) \text { Terhadap } P(\alpha 2)=\frac{p(R)}{p(C)}=\frac{0,8}{0,4}=\frac{8}{4}
$$$$
=2
$$

f. Perbandingan antara Probabilotas variable I terhadap A

$P(\alpha 1)$ Terhadap $P(\alpha 2)=\frac{p(I)}{p(A)}=\frac{0,7}{0,8}=\frac{7}{8}$

g. Perbandingan antara Probabilotas variable I terhadap S

$$
P(\alpha 1) \text { Terhadap } P(\alpha 2)=\frac{p(I)}{p(S)}=\frac{0,7}{0,4}=\frac{7}{4}
$$

h. Perbandingan antara Probabilotas variable I terhadap E

$P(\alpha 1)$ Terhadap $P(\alpha 2)=\frac{p(I)}{p(E)}=\frac{0,7}{0,8}=\frac{7}{8}$

i. Perbandingan antara Probabilotas variable I terhadap C

$P(\alpha 1)$ Terhadap $P(\alpha 2)=\frac{p(I)}{p(A)}=\frac{0,7}{0,4}=\frac{7}{4}$ 
j. Perbandingan antara Probabilotas variable A terhadap S

$$
\begin{gathered}
P(\alpha 1) \text { Terhadap } P(\alpha 2)=\frac{p(A)}{p(S)}=\frac{0,8}{0,4}=\frac{8}{4} \\
=2
\end{gathered}
$$

k. Perbandingan antara Probabilotas variable A terhadap $\mathrm{E}$

$$
\begin{gathered}
P(\alpha 1) \text { Terhadap } P(\alpha 2)=\frac{p(A)}{p(S)}=\frac{0,8}{0,8}=\frac{8}{8} \\
=1
\end{gathered}
$$

1. Perbandingan antara Probabilotas variable A terhadap C

$$
\begin{gathered}
P(\alpha 1) \text { Terhadap } P(\alpha 2)=\frac{p(A)}{p(C)}=\frac{0,8}{0,4}=\frac{8}{4} \\
=2
\end{gathered}
$$

m. Perbandingan antara Probabilotas variable $S$ terhadap $\mathrm{E}$

$$
\begin{gathered}
P(\alpha 1) \text { Terhadap } P(\alpha 2)=\frac{p(S)}{p(E)}=\frac{0,4}{0,8}=\frac{4}{8} \\
=0,5
\end{gathered}
$$

n. Perbandingan antara Probabilotas variable $S$ terhadap $C$

$$
\begin{gathered}
P(\alpha 1) \text { Terhadap } P(\alpha 2)=\frac{p(S)}{p(C)}=\frac{0,4}{0,4}=\frac{4}{4} \\
=1
\end{gathered}
$$

o. Perbandingan antara Probabilotas variable E terhadap C

$$
\begin{gathered}
P(\alpha 1) \text { Terhadap } P(\alpha 2)=\frac{p(E)}{p(C)}=\frac{0,8}{0,4}=\frac{8}{4} \\
=2
\end{gathered}
$$

Kesimpulan hasil diatas adalah Teorema dan probalitas digunakan untuk validasi nilai perbandingan variable, perbandingan variable bisa dikatakan valid jika nilai dari perbandingan antara variable satu dengan variable pembandingnya bernilai sama dengan perbandingan probabilitas variable satu dengan probabilitas variable pembandingnya.

Berdasarkan analisis masalah yang telah disebutkan, maka dipilihlah solusi terbaik untuk menyelesaikan masalah tersebut yaitu dengan pembuatan system pakar untuk mendiagnosa minat remaja khususnya siswa SMA menggunakan model RIASEC berbasis website. Pemilihan platform website dikarenakan dapat diakses secara mudah dan tidak perlu instal aplikasi hanya tinggal membuanya di browser baik desktop maupun smartphone. Sebagai parameter dan juga penentuan tentang minat dari seseorang, penulis menggunakan model RIASEC untuk mendapatkan hasil terbaik.

\section{Referensi}

[1] V. Hedrih, M. Stošić, I. Simić, S. Ilieva "Evaluation of the hexagonal and spherical model of vocational interests in the young people in Serbia and Bulgaria". Serbia Psychological Assosiation, 49(2), 199-210, 2016

[2] S. M. Saadullah, Z. K. A. Shawish, A. Abdulbasith, "Personality Types and Accounting Subfields. Academy of Accounting and Financial Studies Journal, 21, page 1-16, 2017.

[3] R. Moyo-Acerado, L.W. Rabago, and B. T. Tanguilig, Competency Model for Information Systems Specialization Track Utilizing RIASEC and Value Search Models. Computer Science \& Information Technology (CS \& IT), 123-134. 2014.

[4] S. M. Saadullah, A. Shawish, Personality Types and Accounting Subfields. Academy of Accounting and Financial Studies Journal, 21, 1-16.

[5] N. Aljojo, \& H. Saifuddin, A Study of the Reliability and Validity of Holland's RIASEC of Vocational Personalities in Arabic. American Journal of Information Systems. 5(1), 33-37, 2017.

[6] Kurniawati, Inayah. 2015. Rancangan Bangun Aplikasi Tes Psikologi“"HoTest” (HOLLAND ADVANCED-STUDY TEST) denganMenerapkan AlatUkur SDS (SELF-DIRECTED SEARCH. Program Strata 1. Universitas Negeri Semarang. Semarang.

[7] Mary-Catherine., E, McClain, \& C.R, Reardon, Counseling in the Information Age: Using Theory and Art to Analyze Labor Market Informatio. ACA Knowledge Center. 29, 2016. 